\title{
Making Information Systems less Scrugged: Reflecting on the Processes of Change in Teaching and Learning
}

\author{
Luke Houghton \\ Alison Ruth \\ Griffith University, Queensland, \\ Australia \\ La Trobe University, Victoria, \\ Australia
}

\section{L.Houghton@griffith.edu.au}

\section{Executive Summary}

Deep and shallow learner approaches are useful for different purposes. Shallow learning can be good where fact memorization is appropriate, learning how to swim or play the guitar for example. Deep learning is much more appropriate when the learning material present involves going beyond simple facts and into what lies below the surface. When students are asked to think about how facts are created and what they mean, then deep learning is needed. Deep learning requires students to think about the conceptual material used to construct a theory and to reflect on its meaning until they understand and can reconceptualise the item under study. Some forms of learning are more conducive to approaches that do not need deep reflection, although this process invariably brings greater learning potential. This paper outlines a course that was considered by the authors to be 'scrugged'. The word scrugged is defined as 'rough' as in 'it's been a scrugged day." This word arose in a teaching and learning environment in South Australia and was shared on a social networking site. Use of this term seems appropriate in a discipline based on continual change. The rough 'scrugged' approach of the standard information systems fare presents a real problem for Information Systems (IS) Academics because it gives IS the 'shallow' treatment. It is at best a loosely joined mix of concepts coming from multiple directions which does not present a useful framework for theory and instead presents a very thinly constructed grouping of concepts that are superficially treated. The shallow conceptual structure leaves no room for reflective thinking, learning or critical thinking. What results is a good understanding of what kinds of information systems exist, but a very shallow understanding of disciplinary themes and meaning beyond simple artefacts. In this paper, we outline an approach to a course which moved students from shallow repetitive tasks to deep reflective learning around the concepts of Information Systems and discuss the long term implications for Information Systems teaching.

Keywords: Information Systems Education, Technology Education, Learning, Pedagogy.

Material published as part of this publication, either on-line or in print, is copyrighted by the Informing Science Institute. Permission to make digital or paper copy of part or all of these works for personal or classroom use is granted without fee provided that the copies are not made or distributed for profit or commercial advantage AND that copies 1) bear this notice in full and 2) give the full citation on the first page. It is permissible to abstract these works so long as credit is given. To copy in all other cases or to republish or to post on a server or to redistribute to lists requires specific permission and payment of a fee. Contact to request redistribution permission.

\section{Introduction}

Seven years ago the primary author was first asked to teach a variant of a first year information systems course for business (non-IS) students. Students were introduced to the standard first year Management Information Systems textbook approach (see Oz, 2006, for an example). At 
this time, the course was very much what could be described as first-loop learning oriented (Agryris \& Schon, 1996) and deep underpinning concepts were not tested, explored, or developed. Students were instead exposed to a series of concepts about information systems (such as lectures on decision support systems, expert systems, management systems and the tried and tested SDLC - systems development life cycle), and without the proper 'critical' (Mezirow, 1990) transformational aspects of a course that is considered to be part of the adult learning experience (see Meyer, Land, \& Davies, 2006).

Due to the rigid structure of the course, and the perfunctory nature in which topics were presented and delivered, the course suffered at the hands of student evaluations and lacked discernible learning outcomes. Students were not able to move beyond the standard learning of 'facts' and recalling definitions because conceptually the course promoted and incentivised surface level learning approaches. Deep learning and scaffolding were not possible due to the linear structure based on what the authors call the 'shotgun' or 'scrugged' approach to IS. By focusing on a series of concepts about IS instead of the fundamental role of IS in a business context, the students were not able to reflect beyond the series of unrelated concepts to the meta-concepts or core themes of the discipline. Deep learning in this sense became impossible because each week saw a new conceptual structure, new knowledge and in some cases very little thematic content for students to reflect upon.

The course began as a somewhat traditional service course to the Griffith University Business faculty and was aptly named Business Information Systems. In 2007, the course had become unpopular and resulted in what at the time a senior management Professor called the worst rated course in the entire management school, even falling behind Business Statistics! Others researching in the area have come across similar problems (see for example Scime, Andoh-Bandoo, Bush, \& Osatuyi, 2009; Von Hellens, Neilsen, Clayton, \& Beehuyzen, 2009) in regards to the massive scope of information systems teaching. A new team was formed and the resultant processes lead to a reconceptualisation of the subject into the current offering: Business Informatics. During this process the course went from a surface level approach to an approach that focused on deep learning. The Lecturers in the course noticed (semester 12009 ) that the shift has produced some evidence of deep learning around some the core concepts of IS instead of the shallow learning that seemed to follow the previous model.

This paper presents the shift between the two approaches and argues that there is a case to be made for changing courses in IS from a 'scrugged' approach in which shallow learning prevails, to a more thematic offering in which the meta-concepts of IS are teased out, analysed, and reflecting on. The paper introduces the two conceptual structures to show the key differences between the course then and now, and then proceeds to an analysis of recent student data that shows some evidence of learning and reflecting around the deep concepts of IS. The paper concludes with a brief discussion around what the authors hold to be some important implications for IS teaching.

\section{Deep Learning in IS}

In the literature surrounding adult learning, 'Threshold Concepts' (Meyer et al., 2006) bring to attention the idea that some ideas are transformational in that they have the power to open up a deeper learning cycle, at the assumption-shifting level (Agryis, 2008; Mitroff \& Linstone 1993) where students questions their assumptions about what they know and move to the deeper realm of reconceptualisation of ideas and into reflective thinking. In this sense, the original course did not give permission for students to learn because of its overt focus on technical and shallow concepts, what could be called 'the bits and bolts'. Students could literally scour the lecture notes, memorise the concepts given in exam hints and keep learning on the 'surface' level. 
It is a commonly held assumption that student goals and academic goals vary (Linnenbrink, 2005). For example, a student, who has a full-time job, may just be seeking to pass a course instead of learning more deeply about the material and have a variety of other goals from their engagement into the university course. In this case, the student would produce enough work to satisfy the pass criteria and potentially treat the core concepts of the course trivially. What the authors argue here is that often courses that have technical aspirations, such as the introduction to Information Systems type courses, may have a tendency to create and nurture these surface level interactions of the learner. Not only that, but because the material is very shallow and factual, students can engage with the course in absentia through lecture notes, informal social networks, and through the spurious rote learning ventures such as review questions. To add to this is the growing problem of technical sophistication noticed in recent years (Akabulut \& Looney 2009). This does not mean that students should be 'present' in the classroom to learn, what is being argued is that students have the capacity to 'learn enough' in courses where the material is ripe for surface first loop learning interactions.

As noted in the work of Werstch (1998) and more recently Ruth (2004) and Ruth and Houghton (2009), one of the goals of participating in a learning environment for students may be directly related to passing assessment, rather than 'learning for learning's sake' (Ruth, 2004, p. 44). In the case of the IS lecturer, the aim is to teach students what IS is and how it pulls together in a variety of contexts so that students can understand the conceptual structures of IS as a discipline (this is difficult given its trans-disciplinary nature - Galliers, 2003) and understand its role in practice (see also Wang, 2007). The bottom line here is: shallow thin material facilitates single-loop surface learning. The researchers noticed that the course was promoting shallow non-contextual surface learning because the textbooks on offer used a 'shotgun' approach of scattering so much conceptual material on a shallow level that students were learning by rote instead of learning deeply about the role and practice of IS.

This brings into focus some differences between the intentions of students in the course and how the material (and indeed its presentation) shapes and influences the learning of students. In this manner, students often subvert their own processes of learning and avoid constructing deep knowledge about a course by asking simple questions relating to assessment items (e.g., "how do I do this?", rather than "what does this mean?"). An appropriate metaphor would be that of a 'sponge' or 'bucket' because students are asking us to fill them with simple knowledge so they can pass the assessment item or course, instead of asking deeper more relevant questions about the nature of the knowledge they are learning. In the case of this course, the engagement mode (surface level - bits and bolts) actively encouraged the use of surface concepts as a mode of engagement in the IS course. This is turn had the effect of creating a culture of asking questions that were related to assessment (an 'Excel' assignment, a case study, and a final exam) instead of enabling them to reflect and understand more deeply the themes of information systems and how they might be applied in a variety of practical business contexts. Even though case studies may provide an environment for deep learning, there wasn't much evidence. In 2002, there were no mechanisms by which the students could engage in deep learning. The course was designed as a 'shotgun approach' - many ideas shot widely - or 'scrugged' - roughly put together. This is despite the case study approach which can often provoke a sense of deep learning. It was designed to facilitate their memorisation of IS concepts through the rapid introduction of many concepts with no actual deep philosophical or pedagogical foundation. What this means is that the course presented a mode of engagement which said, "here memorise this" instead of, "here are some concepts, reflect on these as you learn them and apply them to this problem." It was basically a platform that promoted a culture of shallow learning and rewarded students for doing it.

In the case of this course, the students were simply taking in the information without 'learning' it and then reproducing it in ways that merely met the course requirements. Recent developments in 
the course however, have produced some promising evidence that students are no longer just participating on a surface level with the course. Fast forward seven years and the same course now introduces students to aspects of deep learning through what course team members consider to be the core meta-concepts of what is needed in an introductory Information Systems course.

\section{Course Structure}

The original structure of the course in 2002 consisted of a series of traditional topics in IS including hardware, basic database development, and types of systems, complemented by computer labs introducing these topics and tutorials working through 'real world' case studies. The main topics are shown in Table 1. In essence the course does make use of concepts such as systems thinking (the 'systems' approach) but for the most part falls under surface level treatment mentioned earlier. Notice also, the disconnect between different weeks, giving the 'shotgun', 'bits and bolts', scrugged approach.

\begin{tabular}{|l|l|}
\hline \multicolumn{1}{|c|}{ Table 1 - Scrugged IS: Shotgun Approach } \\
WOPIC \\
\hline One & Introduction - application of IS to the real world systems approach to problem solving \\
\hline Two & Application and system Software \\
\hline Three & Hardware \\
\hline Four & Database development \\
\hline Seven & Files and Databases \\
\hline Nine & Business models \\
\hline Eleven & Artificial Intelligence DSS, MIS EIS \\
\hline Thirteen & Ethics - security \\
\hline
\end{tabular}

The new course structure is modularized:

Introduction-What is Business Informatics? Systems thinking pillars

Module 1: Business Informatics-Communicating information; Technological challenges to Business; Problem solving in the 21st Century

Module 2: Business Technologies-The history and future of technological innovation; Technologies for personal knowledge management;

Module 3: Real World Informatics-Personal and business decision making; Social networks in the workplace; The Long Tail and new Business Models

Summary-Towards the Next Generation of Business Technologies

The current version of the course is structured around three key themes (modules) bookended by systems thinking concepts (see Jackson, 2003; Waring, 1996). The first lecture introduces systems thinking while the final lecture rounds off and looks to the future reflecting back to the first lecture. There is an underlying approach which links the personal use of computer technology with business use and shows the current embeddedness of technologies in everyday activities. Students are thus moved from an approach in which computer technology and information systems are below conscious level and appear to be a normal part of life (a fundamental trait of the so called 'digital natives' (Prensky, 2001)) to a deeper appreciation of the role information technology, systems and computers play in business, social, and personal areas. 
Systems thinking is introduced through two stories; one is of the recording industry and its perceived negative influence of technology (Mnookin, 2007) and the second is the book market and the positive influence of technology (Amazon.com). These stories set the stage for demonstrating systems thinking and the extensive impact of technology on business in simple, yet compelling stories.

A marked difference in the two approaches is the use of broad themes (deep concepts) versus the outline concepts shown in Table 1 (shallow concepts). The 2002 offering treated each week as a new module and introduced a broad overview of the topic and the progressed through all of the different facts about it. For example, Week Eleven (Table 1) presented a definition of AI and then proceeded through a variety of system types giving them a basic overview and placing them within a linear organisation chart. In contrast the new offering takes students back to the reasons for ICT and the foundational aspects for their existence. Wherever possible, new technologies and Rich Internet Applications (see Table 2) are introduced and critiqued within the lecture time. This process of critique brings students back to the purpose of systems and allows them freedom to reflect more deeply on their application and use in a variety of contexts. The modular approach allows the re-ordering of concepts essentially taking students through a process that starts at a personal level and moves through to a more business focused approach in information management.

\begin{tabular}{|l|l|}
\hline \multicolumn{2}{|c|}{ Table 2 - Tools and technologies used in the course } \\
\hline \multicolumn{1}{|c|}{ TECHNOLOGY } & \multicolumn{1}{c|}{ TOOL EXAMPLE } \\
\hline Social Bookmarking & Delicious.com \\
\hline Wikis & Wikipedia.com \\
\hline Presentation applications & Prezi.com \\
\hline Productivity software & Google Apps for Business \\
\hline Visualisation software & Many Eyes, Wordle \\
\hline
\end{tabular}

The tutorial activities engage students with the fundamental aspects of information management as a key theme of information systems. Each activity engages students in hands on work with computerised systems within a business context. The use of new technologies (e.g., wikis, blogs, social bookmarking) are used hand in hand with traditional business applications, such as spreadsheets, presentation software, and other database driven applications. The series of activities is as follows:

Looking and Listening - gathering data/information

Reading and writing - readability in the information age

The problem of importance - cleaning up data, defining information

Shifts in perception - summarising numerical data

Categorising information - listing, tagging and clouds

Graphs as business knowledge - summarising data for understanding

Reflection on Information Seeking

Social networks - are they appropriate at work?

Finding and analysing niche markets

Reflections on the course

These activities parallel the requirements for the assessment providing a scaffolded approach to the major assessment piece called the 'Business Analysis'. In the last iteration of the course, we chose a current concern of many businesses, specifically, the use of the Internet at work, due to 
the many news articles that seem to be published with about an even split between the 'it's good' and 'it's bad' perspectives. Students must analyse some data that includes a selection of websites and usage for different organisational departments. Additional information is provided about the number of employees per department, the average pay rate per employee per department, the notional work week-length, the proportion of time they are customer facing, and the number of sick days per year per department. Some of this information is irrelevant to the analysis, although students have been quite creative with the data.

The assessment approach includes Collaborative Workshop Exercises (CWE) and the Business Analysis in the following order of submission:

CWE Task 1: Learningfast Competency based assessment of core computer use skills Week 4

CWE Task 2: Wiki Competency Introduction to wiki editing (development of a personal page introducing themselves to the tutorial group) Week 5

CWE Task 3: Library Research Tutorial Competency based assessment on the use of Library databases and research skills Week 6

CWE Task 4: (a) Web Resource and (b) Annotation Wiki-based collaborative analysis of a web site (from the list) and a research paper Week 8

Business Analysis

Spreadsheet analysis of the data and design of a presentation (powerpoint) or report of key outcomes of that analysis Week 11

CWE Task 5: Learning Reflection

Response to 5 questions about their learning in the semester Week 13

These tasks are complemented with an exam in the exam period.

All students must undertake the competency based assessment items and are awarded all marks for completion of these activities at $80 \%$ competency level. This is designed to give students recognition for prior learning, consolidate skills already acquired, and/or establish a minimum level of competency in the use of productivity software (word processing, spreadsheeting, and presentation). It also sets the stage for successful learning by providing a useful, but simple beginning set of tasks. These skills form the foundation of the following activities with Tasks 2 and 4 building on word processing and the Business Analysis building on spreadsheeting and presentations. This ensures that the major productivity applications for business are explored and assessed within the course. Research skills are developed in Task 3 and practiced and assessed in Task 4. The combined work completed in Tasks 1 to 4 are also practiced and assessed in the Business Analysis. The loop is closed with the reflection which allows students to explore what they have learnt and provides valuable insights into the working of the course for the convenors. We provide 5 questions for reflection (Table 3) and it is through these questions that we are able to assess what kind of learning approach has been used. 


\section{Table 3 - Instructions for reflection on learning}

Think about what you have produced for these assignments, the activities you have undertaken within the course, and the things you have learnt. You will need to write a reflection of about 200 words. Use these questions as a guide to writing your reflection.

\section{Questions}

- What helped you to learn?

- What activities made you think?

- What activities would you approach differently?

- What kinds of activities would you have liked to do more of? Less of?

- How useful do you think informatics is?

The reflection serves a number of purposes. It enables the possibility of deep learning for students whilst at the same time allowing the Lecturers to see what works well and what doesn't. As per usual, student evaluations were also used, but the course team also collected feedback from these reflections and used these to shape and redefine the course. What was noticed in Semester 12009 , and in more recent semesters, was that students were beginning to build a better perspective of the course and in some cases there was evidence of genuine reflective thinking. This was an improvement on the aforementioned questions that usually came from students in the old approach that were purely directed at how to successfully complete the assessment tasks. The main reason being that some students now are reflecting on the material and seeking meaning (as discussed later) instead of simply asking how to get through the course. This shift in thinking noted by the course team was noticed as a reaction to the changes made to the assessment and conceptual structure of the course. As a means of introductory evidence to support this assertion, some early evidence of deep learning is offered later in the paper.

\section{The Reflection Task}

As the reflection is only worth 4\%, some (approximately 5-10\%) students choose not to submit, showing a complete lack of engagement and reflective ability almost in line with the previous version of the course. These students approach the course as a hurdle to get over in order to fulfil the requirements for their degree and do not see any value in the smaller tasks of the course. The remaining 242 students submitted reflections, which were assessed using the SOLO (Structure of Observed Learning) taxonomy (Biggs \& Collis, 1982), which evaluates against students' ability to generalise beyond the given concepts. This framework is supplied to them early in the semester and is used for most of the assessment tasks. (For a simplified version of the SOLO taxonomy see http://www.learningandteaching.info/learning/solo.htm)

Students approached this reflection in at least three different ways (Table 4). The first is a 'question-response' format which uses the verbatim questions as headings and tends to favour surface learning approaches. The second is a more generalised approach using some paragraph structure, but still utilising the key terms from the questions. These generally give 5 paragraphs - one for each question or 3 headings - one for each theme - learning, activities and usefulness. These students have begun to reflect but have hesitated to move beyond the structure provided. The final form is a more freeform paragraph approach which may be a single paragraph or multiple paragraphs. Students using this approach seem to reframe the questions within their reflective framework, or go beyond the simple responses to a holistic approach, of a whole of course reflection. The length of the response may be a single 'stream of consciousness' paragraph or a more elabo- 
rate and holistic multi-paragraph structure. Generally, the more structured the response is away from direct answers to these questions, the greater the reflective deep learning processes have been used. It should be noted that while the required length for the reflection is 200 words, the longest reflection submitted was 1124 words long and began with a story from primary school.

\begin{tabular}{|l|l|}
\hline \multicolumn{2}{|c|}{$\begin{array}{c}\text { Table } 4 \text { - Number of Students using different approaches to the reflection } \\
\text { ASSESSMENT APPROACH }\end{array}$} \\
\hline NUMBER OF STUDENTS \\
\hline Questions as headings & 37 \\
\hline Five section/three headings approach & 35 \\
\hline Freeform & 71 \\
\hline
\end{tabular}

\section{Reflections from Students}

As evidence of the reflective capabilities being developed by students, many of the reflections show that students have gained an understanding of the holistic nature of Information Systems in modern society. For instance:

I believe informatics is very useful, as I will continue to use these skills throughout university and working life. Information is everywhere, and the skills learnt in this course helped teach me to locate the information I need, the different forms that information can be presented in, and how to analyse and manipulate this information in various ways, to come up with the necessary result. (Female student, local)

This student appears to have perceived the generality of systems thinking and the applicability of Information Systems in both business and personal areas. Similarly, students are able to appreciate the nature of systems thinking as an approach to problem solving:

In my opinion, the problem solving helps my learning about all subjects. It makes me think a question from different ways, so that I can solve question in different ways while I meet a problem about something else. (Male student, International)

The systems thinking approach introduced in the first week provides a solid foundation for students to build upon and indeed promotes higher level thinking in many students.

Certain activities induced a higher level of thinking by layering the applications of systems with current business and by illustrating their role in, and how these concepts apply to, business. This was especially apparent when working on the Business Case Analysis where information had to be cleaned, manipulated, sorted, retrieved and presented in a logical manner to management. (Female, local)

Perhaps most significantly, the shifts that students experience appear to traverse cultural boundaries, providing both local and international students with a solid foundation upon which to build deeper approaches to learning.

At the very beginning of the course, I thought that Informatics was just about generally getting informations but these lectures and tutorials have given me different ways to look at Informatics and also several basic computer skills and using web resources throughout tutorials. Informations is all around us and the matter is how we use them and analyse them. To use them effectively, a way of thinking, such as system thinking, is crucial. In this point, the lectures have given me opportunities to think differently and systematically. It was very new thing to try to develop thoughts in lecture rather than getting just knowledges and skills. I think it is brilliant. Oth- 
erwise, in the tutorials, I have learned important skills to be successful in university study, such as wiki, library research, excel and annotation. I really liked the business analysis. As this course name is Business Informatics, the connection of business and informations was interesting for me. It was a mixtures of system thinking, filtering information and computer skills. (Male student, international)

This student demonstrates particularly the move from the Confucian heritage learning patterns (Biggs, 1996) to a deeper appreciation of systems thinking as a way of interpreting information and the world around him. It should be noted here this student gained this experience in lectures. The course team realises that this is not a common experience, but this reflection here is cited as example of what's possible. The course team has also received evidence from course evaluations that indicate the opposite.

However, some students have made connections that were embedded into the overall process of study and assessment. The scaffolded tasks allow students to successfully navigate a complex set of tasks which are indicative of approaching a potential problem in the workplace.

The over-all assessment made me think because I saw it as an interconnected process - a bit like having a blank canvas and then adding various layers of paint to create a picture. I appreciated the assessment items as they built-up one on top of the other. They collectively became a process which illustrated how aggregate data that looks confusing and seemingly meaningless gets disaggregated into information and processed and reduced until it is user-friendly, relevant and comprehensible. It was an effective way of illustrating information management using technology, the applicability to business and the various ways and methods that information can be interpreted and displayed. (Female, local)

One of the learning opportunities provided by the course structure is the meta-level interconnectedness of the assessment tasks. Students appear to grasp this in ways not specifically discussed in the course. This leads some students to genuine reflective thinking such as demonstrated by the following student:

This subject makes you think about what [you] see and hear differently. It makes you think just because you see it that doesn't mean that's how it is. This course goes and explains that simple changes in sentences or random bits of data have meanings to them. (Female student, local)

This student has begun to process data and information at a meta-level, seeing conceptual connections where none were previously obvious. In part, the use of the SOLO taxonomy, foregrounding metacognitive processes in the assessment tasks, has assisted students to step beyond rote learning into relational and extended abstract levels. This is clearly an unexpected outcome for some students.

\section{Implications for Teaching and Learning in IS}

The new course structure has provided opportunities for students to engage more deeply in the learning activities in the course and develop deeper awareness of the role of Information Systems in business. There are a number of key 'threshold concepts,' most obviously the introduction to problem solving and, of course, the systems thinking approach. For some students these become foundational for their learning and enable deeper learning and leveraging multiple perspectives. The initial introduction of systems thinking via two powerful stories, in part, sets the stage for an introduction to a longer process of interaction for students with various technology based business models which are shaping our world. This in turn shows students the depth of the problem with modern technology in an environment that changes rapidly every year. These stories become 
a form of 'threshold concept' that allows students to begin questioning information systems in an almost Heidegerrian way (Heidegger, 1977).

Although the development of the course is still ongoing and the course structure is only now stabilising, there are some clear implications about IS and deep learning that arise. Teaching and learning activities in IS are not purely technical, even though that is an important part of what is required. There are key underlying concepts that shape and define what IS is and these form the basis for discussion, even though they may not be agreed on (Mingers \& Stowell, 1997) or even clearly defined (Galliers, 2003; Mingers, 2004). These meta-concepts (such as the systems concept) form the basis for how IS was made and how it became what it is today. By structuring discussions and analysis around key activities that are unique to the IS (i.e. Business Analysis) it can produce a deeper level of understanding about the nature of practice. This in turn creates an engagement mode for students that is conceptual (meta-concepts) whilst showing them the practical side of IS. This changes the mode of engagement for the student, which in turn creates the possibility of deep learning. By shifting the focus in this course from the 'scrugged' approach to one that uses concepts to understand theory and practice, a mode of deep learning became evident through the student reflection data. The change of engagement mode noticed in key students was, in essence, facilitated by the course team's decision to go deeper into the conceptual frames that surround IS and then asking students to reflect on them through the practical assignments and student reflections.

The move from the shallow 'scrugged' approach enabled students to create perspectives on courses surrounding IS at the first point of entry, instead of presenting students with the conceptual equivalent of an ala-carte. The team noticed a shift in what students said in reflective material, which gave some cursory evidence that deep learning is starting to happen. The evidence of such learning was something one of the authors had not noticed from teaching into the course since 2002. The inherent reflectivity of the course appears to facilitate a shift in the understanding of the deeper more relevant parts of IS and not the surface level of IS. As this research is on going and these results are preliminary the long-term implications of this shift may not be evident for some time. However, the outcomes so far have presented a noticeable shift in the course which has both improved the way it's received by students (no longer the worse ranked course) and the way in which they interact with IS theory and practice.

\section{Long Term Implications for Information Systems Teaching}

The problem perceived from this research could be summarised by the following sentence: Information systems teaching is far too thin, conceptually speaking, and needs to rediscover themes for theoretical consideration. What this means is that a core part of learning is reflection on concepts and it is hard to imagine that this could happen if students are treated to a learning environment where IS is treated as if it is a spurious shallow discipline with many seemingly unconnected concepts. A further argument could be posited that suggests IS has no essential theory or a set of core foundational concepts outside of the technical artefact as Galliers' (2003) earlier article suggests. This makes engagement with the course concepts and comprehension of IS very difficult for the learner.

As noted in this research, there was a shift in the understanding of the relevant parts of IS, its constituent parts, the relevancy of it as a discipline, and the core ideas it stands for. These ideas centre around understanding what information means, how it relates to problem solving and decision making, and the role IS has in presenting itself to the broader academic community. A lot of the reflective material analysed presented the notion that Information Systems is a hidden discipline that once explored, reveals itself as relevant, timely and appropriate in an age where we are 
seeking to reinterpret computers for our use in everyday lives. This is perhaps the most surprising finding that shallow textbooks and thin conceptual material prevent learning in some cases and this in turn creates a poor reflection of a broader discipline. This is exemplified by a recent incident involving simple approaches to web searching resulting in individuals being unable to distinguish between a red web site (ReadWriteWeb) and Facebook (blue themed). Simple scrugged approaches to learning about technology lead individuals to search for 'facebook login', clicking the first link and then being confused by an unexpected outcome. Providing individuals with opportunities to investigate and reflect upon a complete problem solving process will hopefully prevent scrugged approaches to the use of technology.

In closing the paper it is important to remember that as IS scholars we are not interested in what technology is or even how we use it, the focus is on what it means. If students cannot find that meaning and take it forward into the workplace with them, the chances are they will simply refer to IS as a purely technical discipline that has no relevance outside of the artefact. The authors hope that this will not prevail but given the downturn in investment and student numbers it appears that it may be inevitable.

\section{References}

Agryis, C. (2008). Teaching smart people how to learn. USA: Harvard Business School Press.

Agryis, C., \& Schon, D. (1996). Organisational learning II: Theory, method and practice. USA: AddisonWesley.

Akbulut, A. Y., \& Looney, C. A. (2009). Improving IS student enrollments: Understanding the effects of IT sophistication in introductory IS courses. Journal of Information Technology Education, 8, 87-100. Retrieved from http://www.jite.org/documents/Vol8/JITEv8p087-100Akbulut297.pdf

Biggs, J. (1996). Western misperceptions of the Confucian-heritage learning culture. In D. Watkins \& J. Biggs (Eds.), The Chinese learner: Cultural, psychological and contextual influences (pp.45-67). Hong Kong: CERC \& ACER.

Biggs, J., \& Collis, K. (1982). Evaluating the quality of learning: The SOLO taxonomy. New York: Academic Press

Galliers, R. D. (2003). Change as crisis or growth? Toward a trans-disciplinary view of Information Systems as a field of study - a response to Benbasat and Zmud's call for returning to the IT artifact. Journal of the Association for Information Systems, 4(1), 337-351.

Heidegger, M. (1977). The question concerning technology and other essays. New York: Harper and Row.

Jackson, M. C. (2003). Systems thinking: Creative holism for managers. Wiley.

Linnenbrink, E. A. (2005). The dilemma of performance-approach goals: The use of multiple goal contexts to promote students' motivation and learning. Journal of Educational Psychology, 97(2), 197-213.

Mezirow, J. (1990). Fostering critical reflection in adulthood. San Francisco: Jossey-Bass.

Meyer, J. H. F., Land, R., \& Davies, P. (2006). Implications of threshold concepts for course design and evaluation. In J. H. F. Meyer \& R. Land (Eds.), Overcoming barriers to student understanding: Threshold concepts and troublesome knowledge (pp 195-206). London and NewYork: Routledge.

Mingers, J. (2004). Real-izing Information systems: Critical realism as an underpinning philosophy in information systems. Information and Organisation, 14, 87-103.

Mingers, J., \& Stowell, F. (1997) Information systems: An emerging discipline? UK: John Wiley.

Mitroff, I. \& Linstone, H. (1993). The unbounded mind. USA: Oxford University Press.

Mnookin, S. (2007). Universal's CEO once called iPod users thieves. Now he's giving songs away. Wired Magazine, 15(12). Retrieved July 2009 from http://www.wired.com/entertainment/music/magazine/15$\underline{12 / \mathrm{mf} \text { morris }}$ 
Oz, E. (2006). Management information systems (6th ed.). USA: Course Technology.

Prensky, M. (2001). Digital immigrants, digital natives. On the Horizon, 9(5), 2-15.

Ruth, A. (2004). Learning at the Screenface: A pentadic analysis of email discussion lists. Unpublished doctoral thesis, Griffith University, Australia.

Ruth, A., \& Houghton, L. (2009). The wiki way of learning. Australasian Journal of Educational Technology, 25(2), 135-152.

Scime, A., Andoh-Bandoo, F. K., Bush, C., \& Osatuyi, B. (2009). Information systems' diverse origins coming together. Journal of Information Technology Education, 8, 193-208. Retrieved from http://www.jite.org/documents/Vol8/JITEv8p193-209Scime703.pdf

Von-Hellens, L., Clayton, K., Neilsen S., \& Beekhuyzen, J. (2009). Perceptions of ICT careers in German Schools: An exploratory study. Journal of Information Technology Education, 8, 211-228. Retrieved from http://www.jite.org/documents/Vol8/JITEv8p211-228vonHellens716.pdf

Wang, S. (2007). An examination of the introductory MIS Course. Journal of Information Technology Education, 6, 135-152. Retrieved from http://www.jite.org/documents/Vol6/JITEv6p135152Wang203.pdf

Waring, A. (1996). Practical systems thinking. UK: Cengage Learning.

Wertsch, J.V. (1998). Mind as action. New York: Oxford University Press.

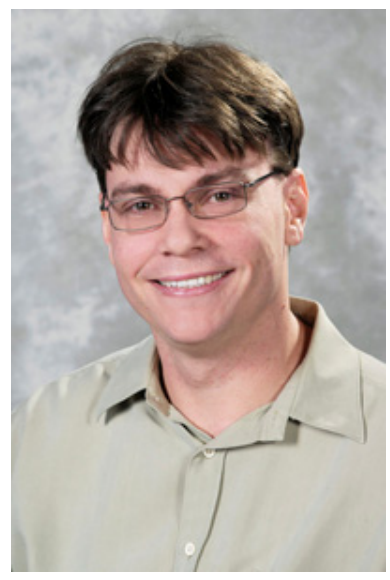

\section{Biography}

Dr. Luke Houghton is a Lecturer in Information Systems in the Department of International Business and Asian Studies, in the Griffith Business School at Griffith University, Queensland Australia. He has been researching the link between how thinking effects problem solving and decision making in complex environments for eight years. $\mathrm{He}$ was awarded his $\mathrm{PhD}$ in 2008, and has publications in the Journal of the Operational Research Society, Systems Research and Behavioural Science and The Australasian Journal of Educational Technology. He has also reviewed papers for Information Systems Journal.

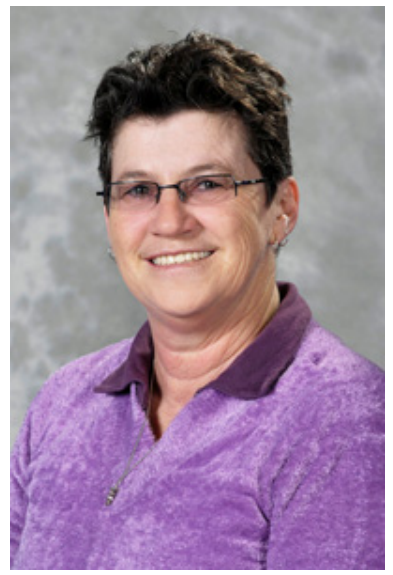

Dr. Alison Ruth is an Academic Curriculum Designer with the Faculty of Law and Management at La Trobe University, Melbourne, Australia. She was previously a Lecturer in Information Systems in the Department of International Business and Asian Studies, in the Griffith Business School, Griffith University, Queensland Australia. Alison's primary research interests centre around online learning interactions, computer mediated learning environments and educational pedagogy and philosophy. She has papers published in the Australiasian Journal of Educational Technology and The Journal of Teacher Education. Alison's teaching excellence was recognized last year with several award nominations. 